\title{
135La as an auger-electron emitter for targeted internal radiotherapy
}

Fonslet, Jesper; Lee, Boon Quan; Tran, Thuy A.; Siragusa, Mattia; Jensen, Mikael; Kibedi, Tibor; Stuchbery, Andrew E.; Severin, Gregory

\section{Published in:}

Physics in Medicine and Biology

Link to article, DOI:

10.1088/1361-6560/aa9b44

Publication date:

2018

Document Version

Peer reviewed version

Link back to DTU Orbit

Citation (APA):

Ţ̧gsslet, J., Lee, B. Q., Tran, T. A., Siragusa, M., Jensen, M., Kibedi, T., Stuchbery, A. E., \& Severin, G. (2018).

$\mathrm{La}$ as an auger-electron emitter for targeted internal radiotherapy. Physics in Medicine and Biology, 63(1), [015026]. https://doi.org/10.1088/1361-6560/aa9b44

\section{General rights}

Copyright and moral rights for the publications made accessible in the public portal are retained by the authors and/or other copyright owners and it is a condition of accessing publications that users recognise and abide by the legal requirements associated with these rights.

- Users may download and print one copy of any publication from the public portal for the purpose of private study or research.

- You may not further distribute the material or use it for any profit-making activity or commercial gain

- You may freely distribute the URL identifying the publication in the public portal 


\section{ACCEPTED MANUSCRIPT}

\section{5 La as an auger-electron emitter for targeted internal radiotherapy}

To cite this article before publication: Jesper Fonslet et al 2017 Phys. Med. Biol. in press https://doi.org/10.1088/1361-6560/aa9b44

\section{Manuscript version: Accepted Manuscript}

Accepted Manuscript is "the version of the article accepted for publication including all changes made as a result of the peer review process, and which may also include the addition to the article by IOP Publishing of a header, an article ID, a cover sheet and/or an 'Accepted Manuscript' watermark, but excluding any other editing, typesetting or other changes made by IOP Publishing and/or its licensors"

This Accepted Manuscript is @ 2017 Institute of Physics and Engineering in Medicine.

During the embargo period (the 12 month period from the publication of the Version of Record of this article), the Accepted Manuscript is fully protected by copyright and cannot be reused or reposted elsewhere.

As the Version of Record of this article is going to be / has been published on a subscription basis, this Accepted Manuscript is available for reuse under a CC BY-NC-ND 3.0 licence after the 12 month embargo period.

After the embargo period, everyone is permitted to use copy and redistribute this article for non-commercial purposes only, provided that they adhere to all the terms of the licence https://creativecommons.org/licences/by-nc-nd/3.0

Although reasonable endeavours have been taken to obtain all necessary permissions from third parties to include their copyrighted content within this article, their full citation and copyright line may not be present in this Accepted Manuscript version. Before using any content from this article, please refer to the Version of Record on IOPscience once published for full citation and copyright details, as permissions will likely be required. All third party content is fully copyright protected, unless specifically stated otherwise in the figure caption in the Version of Record.

View the article online for updates and enhancements. 


\title{
${ }^{135}$ La as an Auger-electron emitter for targeted internal radiotherapy
}

J. Fonslet ${ }^{1}$, B.Q. Lee ${ }^{2,3}$, T.A. Tran ${ }^{4}$, M. Siragusa ${ }^{1}$, M. Jensen ${ }^{1}$, T. Kibédi ${ }^{3}$, A.E. Stuchbery ${ }^{3}$, G.W. Severin $^{1,5,6^{*}}$

${ }^{1}$ Hevesy Laboratory, Center for Nuclear Technologies, Technical University of Denmark, Roskilde, Denmark

${ }^{2}$ Department of Oncology, Oxford University, Oxford, United Kingdom

${ }^{3}$ Department of Nuclear Physics, Australia National University, Canberra, Australia

${ }^{4}$ Lund University Bioimaging Center, Lund University, Lund, Sweden

${ }^{5}$ Department of Chemistry, Michigan State University, East Lansing, MI, USA

${ }^{6}$ Facility for Rare Isotope Beams, Michigan State University, East Lansing, MI, USA

\begin{abstract}
:
Introduction: ${ }^{135} \mathrm{La}$ has favorable nuclear and chemical properties for Auger-based targeted internal radiotherapy. Here we present detailed investigations of the production, emissions, and dosimetry related to ${ }^{135}$ La therapy.

Methods and Results: ${ }^{135} \mathrm{La}$ was produced by $16.5 \mathrm{MeV}$ proton irradiation of metallic ${ }^{\text {nat }} \mathrm{Ba}$ on a medical cyclotron, and was isolated and purified by trap-and-release on weak cation-exchange resin. The average production rate was $407 \pm 19 \mathrm{MBq} / \mu \mathrm{A}$ (saturation activity), and the radionuclidic purity was $98 \%$ at $20 \mathrm{~h}$ post irradiation. Chemical separation recovered $>98 \%$ of the ${ }^{135}$ La with an effective molar activity of 70 $\pm 20 \mathrm{GBq} / \mu \mathrm{mol}$. To better assess cellular and organ dosimetry of this nuclide, we have calculated the Xray and Auger emission spectra using a Monte Carlo model accounting for effects of multiple vacancies during the Auger cascade. The generated Auger spectrum was used to calculate cellular S-factors.

Conclusion: ${ }^{135} \mathrm{La}$ was produced with high specific activity, reactivity, radionuclidic purity, and yield. The emission spectrum and the dosimetry are favorable for internal radionuclide therapy.
\end{abstract}

Keywords: lanthanum-135, La-135, radiolanthanide, auger therapy, targeted radionuclide therapy, radionuclide production

* gwseverin@chemistry.msu.edu - corresponding author 
2 The development of targeted internal radiotherapy for cancer and patient specific treatment requires

3 radionuclides with suitable half-lives, chemical properties and emissions. Several nuclides are already in

4 clinical use, notably the beta emitters ${ }^{177} \mathrm{Lu}$ and ${ }^{90} \mathrm{Y}[1,2]$. In addition, preclinical studies with other 5 lanthanides, especially the terbium isotopes ${ }^{149,151,155,161} \mathrm{~Tb}$ show promise, providing a matched set of 6 isotopes with diagnostic positrons and therapeutic alpha- and beta-particles, as well as Auger electrons 7 [3-6]. The radioactive isotopes of lanthanum are chemically similar to the other lanthanides, and one in 8 particular, ${ }^{135}$ La has potential as a therapeutic Auger electron emitter. 9

Auger electron emitters are particularly interesting because they have the capability to deliver radiation dose to individual targeted cells while sparing surrounding tissues. This is in contrast to more commonlyused therapeutic nuclides, like ${ }^{177} \mathrm{Lu}$ and ${ }^{90} \mathrm{Y}$, which have beta emissions that traverse many cell lengths, with dispersed energy deposition. The very low energy and multiplicity of Auger electrons may prove useful in targeted therapy, especially in the treatment of diffuse and disseminated disease, where other nuclear emissions do not allow adequate dose to the targeted cell due to excessive particle range. Further, there is mounting evidence that the relative biological effectiveness (RBE) of multiple low energy electrons $(<10 \mathrm{keV})$ significantly exceeds that of photons and higher energy beta particles [7]. In some cases the biological effect of absorbed dose from Auger electrons is 2-10 times higher than X-rays of the same energy, meaning that these emissions are more potent in introducing radiation damage to living cells [8-10]. Therefore, coupling Auger emitting radionuclides like ${ }^{135}$ La with highly specific targeting vectors, particularly cell-nucleus targeting moieties, has potential as a powerful therapeutic tool.

${ }^{135} \mathrm{La}$ decays by electron capture (EC), primarily ( $>98 \%$ ) to the ground state of stable ${ }^{135} \mathrm{Ba}$, with a halflife of 18.9 hour [11] (Figure 1). Following the decay Auger electrons are emitted which are potentially useful for internal radiotherapy. Throughout this paper we use the term "Auger electrons" as designation for all Auger cascade electrons, including the Coster-Kronig and Super-Coster-Kronig electrons. X-rays 27 accompany the Auger cascade with a spectrum sufficient for Single Photon Emission Computed 28 Tomography (SPECT) imaging/capabilities. In small-animal studies this allows for concurrent SPECT 29 imaging, facilitating dosimetry calculations in small-animal models [12]. In the projected future human 30 use of therapeutic doses, the activity could be high enough to allow whole-body SPECT based on the low 31 abundance (1.5\% branch) $480.5 \mathrm{keV}$ gamma emissions. 
32

\section{$18.93 \mathrm{~h}$}

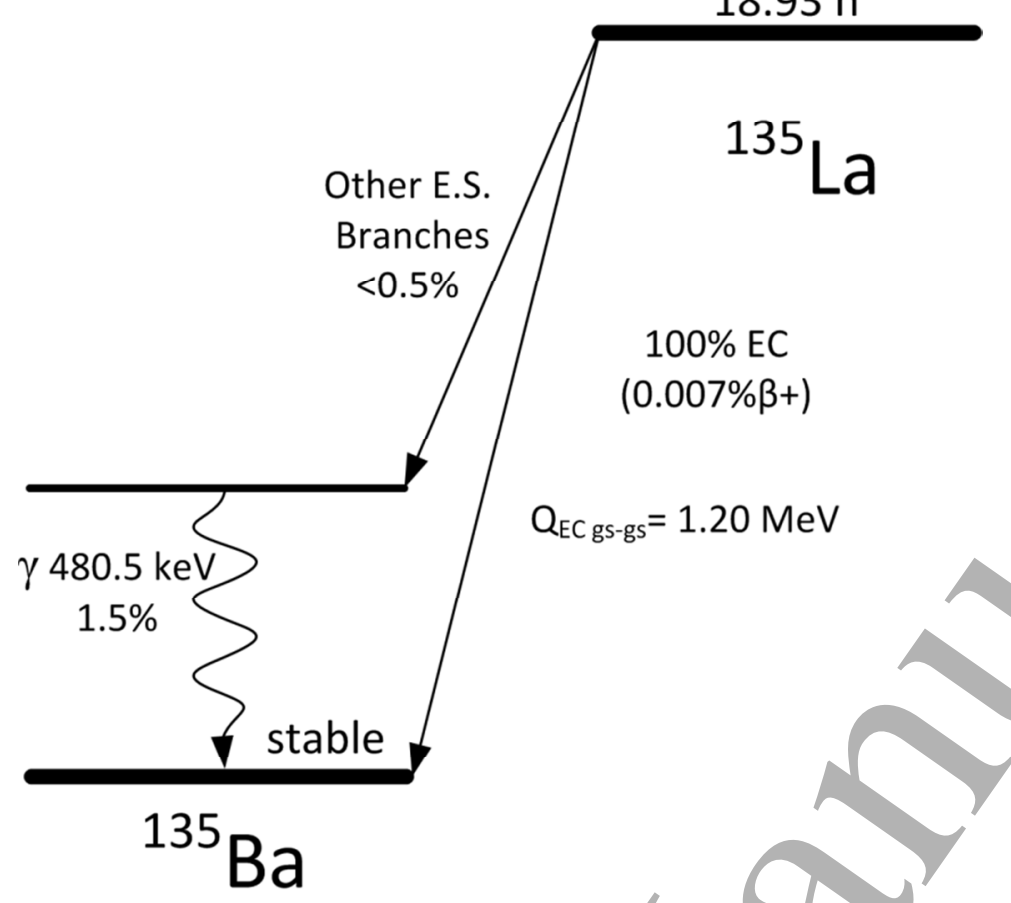

Figure 1 Simplified decay scheme of ${ }^{135}$ La[11,13].

\section{(1)}

When considering employing ${ }^{135} \mathrm{La}$ as a radiotherapeutic nuclide, it is necessary to make detailed dose calculations. This is important not only on the organ/evel, but also on the cellular level, due to the highly localized dose deposition from emitted Auger electrons. In order to get a realistic dose estimate the entire emission spectrum needs to be well understood. The conventionally-used databases (like NuDat 2 [14]) only give a condensed version of the Auger cascade emissions, without addressing the many electrons below $3 \mathrm{keV}$. Lee et al. recently developed an Auger-cascade model, BrIccEmis, based on a Monte Carlo technique for determining $\mathbf{X}$-ray and Auger emission spectra $[15,16]$. For the present work, the model was 2 used to obtain detailed radiation spectra from ${ }^{135} \mathrm{La}$, especially for very low-energy Auger electrons and 3 X-rays. Prescher et al. [17], and Tárkányi et al. [18] determined the production cross-sections for ${ }^{135} \mathrm{La}$ during proton irradiation of ${ }^{\text {nat }} \mathrm{Ba}$ at energies ranging from $12-70 \mathrm{MeV}$. Evident in their data is the fact that ${ }^{135} \mathrm{La}$ is the primary radionuclide with half-life longer than a few minutes produced in the protoninduced reactions on natural barium at energies available on most medical cyclotrons.

In this work, we detail the properties of ${ }^{135} \mathrm{La}$ as a radiotherapeutic nuclide. The practical considerations 9 of production, purification, and radiolabeling are experimentally determined and optimized for the 50 chelator DTPA (diethyeneltriaminepentacetic acid). Additionally, reevaluations of the Auger and X-ray 
emission spectra are presented along with a calculation of the cellular $S$-factors and a dosimetry

52 53 comparison to the commonly used radiotherapeutic isotopes ${ }^{177} \mathrm{Lu}$ and ${ }^{90} \mathrm{Y}$.

\section{Materials and Methods:}

\section{General}

All reagents were obtained from Sigma Aldrich and used without further purification unless otherwise noted. All water was $18 \mathrm{M} \Omega$ MilliQ-grade (Sartorious). Hydrochloric acid (HCl) solutions were diluted from $37 \%$ aq. $\mathrm{HCl}$ (Fluka TraceSelect) with water. $\mathrm{pH}$ was determined by $\mathrm{pH}$ paper (PEHANON 1-12 and 4-9). Gamma spectroscopy was performed on a Princeton Gammatech LGC 5 germanium detector, calibrated using certified ${ }^{133} \mathrm{Ba}$ and ${ }^{152} \mathrm{Eu}$ sources.

\section{Cyclotron Production of ${ }^{135}$ La from ${ }^{\text {nat }} \mathrm{Ba}$}

Chunks of dendritically distilled metallic barium (99.99\% trace metal grade) totaling $314-550 \mathrm{mg}$ were pressed with a hydraulic press $\left(20 \mathrm{kN} / \mathrm{cm}^{2}\right)$ into a $9 \mathrm{~mm}$ diameter $\mathrm{x} 3 \mathrm{~mm}$ deep divot in a $28 \mathrm{~mm}$ diameter x $5 \mathrm{~mm}$ thick silver disc. The barium was immediately covered with either $100 \mu \mathrm{m}$ aluminum or $25 \mu \mathrm{m}$ niobium foil to reduce the exposure to atmospheric oxygen, and placed into a target holder supplying direct water cooling to the backside of the silver. A rough schematic of the target and target holder can be seen in a paper by Severin et al. [19]. The target holder was mounted onto a PETtrace cyclotron (PT800 General Electric) and irradiated at $90^{\circ}$ (normal) incidence with $16.5 \mathrm{MeV}$ protons at $15 \mu \mathrm{A}$ for 235-280 min. Owing to the co-production of short-lived ${ }^{134} \mathrm{La}\left(\mathrm{t}_{1 / 2}=6.5 \mathrm{~min}\right)$ and ${ }^{136} \mathrm{La}\left(\mathrm{t}_{1 / 2}=9.9 \mathrm{~min}\right)$, and slightly longer-lived ${ }^{132} \mathrm{La}\left(\mathrm{t}_{1 / 2}=4.5 \mathrm{~h}\right)$ and ${ }^{133} \mathrm{La}\left(\mathrm{t}_{1 / 2}=3.9 \mathrm{~h}\right)$, the targets were allowed to decay for $12-24$ hours before further handling.

In order to determine the production rates of ${ }^{135} \mathrm{La}$ and the other longer-lived co-produced radioisotopes $\left({ }^{132} \mathrm{La},{ }^{133} \mathrm{La}\right.$ and $\left.{ }^{135 \mathrm{~m}} \mathrm{Ba}\right)$, a single thick target of Ba totaling $472 \mathrm{mg}$ was irradiated at $30 \mu \mathrm{A}$ for 227 minutes. This target was dissolved 19.8 hours post irradiation in $5 \mathrm{~mL} 1.2 \mathrm{M} \mathrm{HCl}$, transferred to a plastic 7 vial, and the radionuclidic contents were quantified by gamma spectroscopy.

\section{Purification of ${ }^{135} \mathrm{La}$}

The cover foil was removed and the silver disc mounted in a dissolution chamber allowing the barium to 81 be dissolved with $2 \mathrm{~mL} 4 \mathrm{M}$ aq. $\mathrm{HCl}$. After complete dissolution of the ${ }^{\text {nat }} \mathrm{Ba}$, the solution was transferred 82 to a vial along with 1-2 $\mathrm{mL}$ of water to rinse. Adding the water also served to dissolve any additional 83 white precipitate present after oxidation of $\mathrm{Ba}$ in $\mathrm{HCl} /$ water. Therefore, concentrated $\mathrm{HCl}$ was added to 84 the dissolved target to bring the $\mathrm{HCl}$ concentration to $1 \mathrm{M}$ acidity in a final volume of $4 \mathrm{~mL}$. The solution 
was then heated at $70{ }^{\circ} \mathrm{C}$ for at least $30 \mathrm{~min}$. The $\mathrm{pH}$ was adjusted to $\sim 6$ with $5 \mathrm{~mL}$ HEPES buffer (4-(2hydroxyethyl)-1-piperazineethanesulfonic acid) (1 M, pH = 7.3, $\mathrm{HCl} / \mathrm{NaOH}$ adj.) and $\mathrm{NaOH}(1 \mathrm{M})$ and passed over $100 \mathrm{mg}$ CM resin (Waters Accell Plus CM weak cation exchange resin) packed in a $4 \mathrm{~mm}$ inner diameter column with polyethylene frits in order to trap the ${ }^{135} \mathrm{La}$. The CM resin had been prepped by sequential washing with $5 \mathrm{~mL}$ acetonitrile, $5 \mathrm{~mL} 0.1 \mathrm{M} \mathrm{HCl}, 10 \mathrm{~mL}$ water, and $3 \mathrm{~mL} 1 \mathrm{M} \mathrm{HEPES} \mathrm{pH}$ 7.3. After trapping the ${ }^{135} \mathrm{La}$, the resin was washed with $25 \mathrm{~mL}$ of water. Finally, the column was eluted with $1 \mathrm{~mL} 0.1 \mathrm{M} \mathrm{HCl}$ to obtain the purified ${ }^{135} \mathrm{La}$.

\section{Specific activity measurements}

Analysis by ICP-OES (inductively coupled plasma optical emission spectroscopy) was performed on the samples to determine the non-radioactive, competitive metal content. The trace metals were quantified using a ThermoScientific iCAP 6000 Series instrument with iTeva software. The spectrometer was calibrated against standard solutions containing $\mathrm{La}, \mathrm{Ba}, \mathrm{Cr}, \mathrm{Mn}, \mathrm{Co}, \mathrm{Fe}, \mathrm{Zn}$ and $\mathrm{Cu}$, which were prepared by dissolution and dilution of chloride salts of the tested metals in $0.3 \mathrm{M} \mathrm{HCl}$. Samples for analysis were likewise diluted in $0.3 \mathrm{M} \mathrm{HCl}$.

The effective molar activity was determined experimentally via titration of the purified ${ }^{135}$ La with DTPA. DTPA solutions were prepared in water by serial dilution to make concentrations spanning 8-5000 nM. From these, $400 \mu \mathrm{L}$ of each concentration was moved to an Eppendorf tube and buffered by addition of $100 \mu \mathrm{L}$ of HEPES ( $1 \mathrm{M}, \mathrm{pH}=7.4)$. The molar amount of DTPA used in the titration ranged 3.2-2000 pmol in 5 steps. To each of these Eppendorf tubes, $10 \mu \mathrm{L}$ of $0.1 \mathrm{M} \mathrm{HCl}$ containing 3.5-4.5 MBq of ${ }^{135} \mathrm{La}$ was added bringing the final $\mathrm{pH}$ to $\sim 7$ measured on $\mathrm{pH}$ paper. The titrations were performed in duplicate for each separation $(n=3)$ with one reacting at room temperature and the other reacting at $70{ }^{\circ} \mathrm{C}$. After 30 minutes, the reactions were analyzed by thin-layer chromatography (TLC) performed on aluminumbacked silica (Merck TLC silica gel 60 F254), eluted with 5\% (w/v) ammonium acetate in a 1:1 mixture of methanol and water. In this system La-DTPA moves with the eluent, while un-chelated $\mathrm{La}^{3+}$ remained at the origin. TLC plates were analyzed by autoradiography on a Cyclone Plus Storage Phosphor Scanner 113 showing the chelation ratio closest to $50 \%$ was used to determine the amount of DTPA needed to chelate $114100 \%$ of the added activity and thus the effective specific activity.

115

116 X-ray and Auger emission spectra

117 The initial-vacancy distribution and the energy spectra of X-rays and Auger electrons following the 118 decays of isolated ${ }^{135} \mathrm{La}$ atoms were calculated according to the methodology presented by Lee et al. [16] 
with $10^{5}$ Monte Carlo simulated decays. Both the condensed phase and isolated atom models were used

120 for determining the cascade distributions.

121

122 Dosimetry

123

124 On a cellular scale, dosimetry was treated in two ways: first by use of MIRDCell, a formalism developed 125 by MIRD (Medical Internal Radiation Dose) for calculation of cellular S-values [20,21]; and second by 126 the COOLER code [22]. The S-value is defined as the absorbed dose in the target structure from a 127 radioactive decay in the source structure, typically given in the unit $\mathrm{Gy} /(\mathrm{Bq} \cdot \mathrm{s})$ and denoted as $\mathrm{S}$ (Target $\leftarrow$ 128 Source). In this case, the target was taken to be the cell nucleus. Contributions to the nucleus (N) from the 129 nucleus $(\mathrm{N}), \mathrm{S}(\mathrm{N} \leftarrow \mathrm{N})$, from the cytoplasm $(\mathrm{Cy}), \mathrm{S}(\mathrm{N} \leftarrow \mathrm{Cy})$, and from the cell surface $(\mathrm{CS}), \mathrm{S}(\mathrm{N} \leftarrow \mathrm{CS})$, 130 were separately determined. In this work, we performed MIRD-based calculations, totally within the 131 MIRD framework by taking the individual electron branches (Table 2), evaluating them in MIRDCell, 132 and then summing the doses over all emissions [20]. MIRDCell was also used to calculate the cellular 133 dosimetry of ${ }^{177} \mathrm{Lu}$ and ${ }^{90} \mathrm{Y}$. This gave the MIRD cellular S-values as proxies for the cellular dosimetry for 134 all three isotopes (depending on the target size and source distribution). For the calculations we chose a 135 cell radius of $7 \mu \mathrm{m}$ and nucleus radius of $5 \mu \mathrm{m}$. This allowed comparison with the COOLER formalism 136 (the COOLER V79 cell setting has radii of 7.1 and $5.2 \mu \mathrm{m}$, respectively). COOLER is a new cellular 137 dosimetry approach that uses Monte-Carlo derived/stopping powers (based on PARTRAC simulations 138 [23]). This is in contrast to MIRDCell which uses Cole's electron ranges to derive an electron stopping 139 power [22,24]. The Monte-Carlo derived stopping powers generally result in altered dose distributions, 140 especially for electrons with energies in the range of 5-35 keV, coinciding with the important Auger branches of the lanthanides.

143 In order to predict how a heterogeheously targeted tumor of macroscopic dimensions would receive dose 144 across many cell diameters, electron dose kernels were calculated in two different ways. First, by taking 145 the full electron emission spectrum (including Augers, nuclear beta emissions, and conversion electrons $146[13,14,25])$ and folding it with the range-versus-energy relationship from Cole. The dose-point kernel was 147 calculated in MATLAB for ${ }^{135} \mathrm{La},{ }^{177} \mathrm{Lu}$ and ${ }^{90} \mathrm{Y}$. The calculation was performed using a step-size of 0.2 $148 \mu \mathrm{m}$. Second, the electron dose-point kernel of ${ }^{135} \mathrm{La}$ was also calculated using the COOLER formalism.

\section{Results: \\ 150 Cyclotron Production of ${ }^{135}$ La from ${ }^{\text {nat }} \mathrm{Ba}$}


151 When pressing the barium into the target holder, it was important to move quickly to limit the exposure of 152 the barium to air. Within the minimal ( $\sim 1$ minute) pressing time, a white film was observed to form over

153 the normally shiny barium. The pressed target appeared smooth, and likely had very limited surface area 154 after pressing, as compared to the dendritic chunks. In most experiments, no discoloration or alteration of 155 the target surface was observed after irradiation at a target current of $15 \mu \mathrm{A}$. Both aluminum $(100 \mu \mathrm{m})$ 156 and niobium $(25 \mu \mathrm{m})$ were tested as front foil materials, and we did not observe any qualitative difference 157 in target behavior between the two.

159 The end-of-saturation bombardment (EOSB) yields for the nuclides $\left(t_{1 / 2}>3 \mathrm{~h}\right)$ produced during proton 160 irradiation of ${ }^{\text {nat }} \mathrm{Ba}$ at $15.8 \mathrm{MeV}$ (after degradation in the aluminum cover foil) are given in Table 1.

Table 1: Thick target EOSB yields for proton irradiation of ${ }^{\text {nat }} \mathrm{Ba}$. Only nuclides with $\mathrm{t} / \mathrm{s}>3 \mathrm{~h}$ are listed. $\left.{ }^{*}\right)^{132}$ La is produced both directly and via decay of the co-produced ${ }^{132 \mathrm{~m} L a}$ isomer. The number presented here reflects the amount of ${ }^{132} \mathrm{La}$ produced in total after all ${ }^{132 \mathrm{~m}}$ La has decayed to the ground state. Half-lives were obtained from refs: $[11,13,26]$.

166 Shorter irradiations produced a proportionately larger amount of the short-lived impurities. These short167 lived impurities will, at longer irradiation times, approach saturation and constitute a smaller proportion 168 of the total radioactivity. Therefore the radionuclidic purity of ${ }^{135} \mathrm{La}$ (with respect to the decay rate of the 169 other lanthanum isotopes) increases with irradiation time as long as the ${ }^{135 \mathrm{~m}} \mathrm{Ba}$ impurity is chemically removed.

173 Dissolution of the irradiated ${ }^{\text {nat }} \mathrm{Ba}$ was always rapid (3-5 $\mathrm{min}$ ) in the $\mathrm{HCl}$ solution. The trapping efficiency 174 of ${ }^{135} \mathrm{La}$ on the small column of $\mathrm{CM}$ resin was $>99 \%$. Several loading conditions were tested: with or 175 without the 30 minute heating step, and both ammonium acetate and HEPES buffers were tested: each at $176 \mathrm{pH} 4$ and 6. It was observed that the 30-minute heating at $70{ }^{\circ} \mathrm{C}$ greatly improved trapping. When 177 omitting this step loading efficiencies of only 50\% were observed. Additionally, by re-acidifying and 
178 heating any washed-through solution it was possible to retain all previously untrapped activity on a 179 second column (further illustrating the importance of heating). When comparing the two buffers, 180 ammonium acetate and HEPES, it was found that HEPES at $\mathrm{pH}=6$ resulted in higher trapping efficiency. 181 The $0.1 \mathrm{M}$ hydrochloric acid elution $(1 \mathrm{~mL})$ was $>99 \%$ efficient at releasing the ${ }^{135} \mathrm{La}$.

183 Chemical purity and molar activity measurements

184 ICP-OES analysis revealed the concentration of metal contaminants in the final elution. Barium was still 185 present at a concentration of $3.68 \pm 0.09 \mu \mathrm{g} / \mathrm{MBq}$. Cr, Mn and Fe were measured in concentrations of $1861.64 \pm 1.05 \mathrm{ng} / \mathrm{MBq}, 1.19 \pm 0.81 \mathrm{ng} / \mathrm{MBq}$ and $1.57 \pm 0.33 \mathrm{ng} / \mathrm{MBq}$, respectively. Using the final barium 187 concentration, the separation factor was $138 \pm 36$. In principle, the barium removal could also have been 188 verified by the absence of coproduced ${ }^{135 \mathrm{~m}} \mathrm{Ba}$, as this isotope is not formed by the decay of ${ }^{135} \mathrm{La}$. 189 However, the sensitivity and specificity of the gamma spectroscopy was not sufficient to detect the 190 remaining low level of barium.

192 The molar activity of ${ }^{135}$ La determined by stable lanthanum assay on ICP-OES was over-optimistic for the 193 expected labelling efficiency. This is because any other lanthanide, or similar hard metal ion impurity, 194 could compete for labelling positions on vectors. Instead, the effective molar activity was assessed by 195 thin-layer chromatography analysis of DTPA titrations. In all cases, a small amount $(10-15 \%)$ of ${ }^{135} \mathrm{La}$ 196 remained at the origin of the TLC sheet no matter how large the excess of DTPA. This was believed to be 197 due to formation of an inert lanthanum complex in the labeling solution, but the exact nature of the 198 immobile ${ }^{135} \mathrm{La}$ was not determined. Assuming $10 \%$ of the ${ }^{135} \mathrm{La}$ was thermodynamically unavailable, the 199 DTPA titrations showed an effective molar activity of $70.4 \pm 20.0 \mathrm{GBq} / \mu \mathrm{mol}$.

202 The initial-vacancy distribution for ${ }^{135} \mathrm{Ba}$ following the electron capture (EC) and internal conversion (IC) 203 processes was calculated, and as expected $>99.9 \%$ of the initial vacancies created in atomic shells were 204 due to EC. The resulting total $\mathrm{K}$ vacancy probability was $84.9 \%$ and the total $\mathrm{L}$ vacancy probability was $20511.9 \%$. Internal conversion and electron capture processes in higher shells constituted the remaining 3.2\% 206 of vacancies.

207 The calculated X-ray and Auger spectra following the decay of ${ }^{135} \mathrm{La}$ in the condensed-phase 208 approximation are shown in figure 2. The Auger-cascade simulations give only a small difference in the 209 resulting Auger branching ratios between the condensed-phase (with continuous filling of the outermost 210 vacancies) and isolated-atom approximations. The dose-point kernels derived from the two 211 approximations were found to slightly differ from each other only in the first $100 \mathrm{~nm}$ [27]. For the 
212 purpose of dosimetry and possible therapeutic use, the effect is negligible and the condensed phase 213 spectra were used for dosimetry calculations.

214

Yields per decay and mean energies of the main groups of Auger electrons are summarized in Table 2.
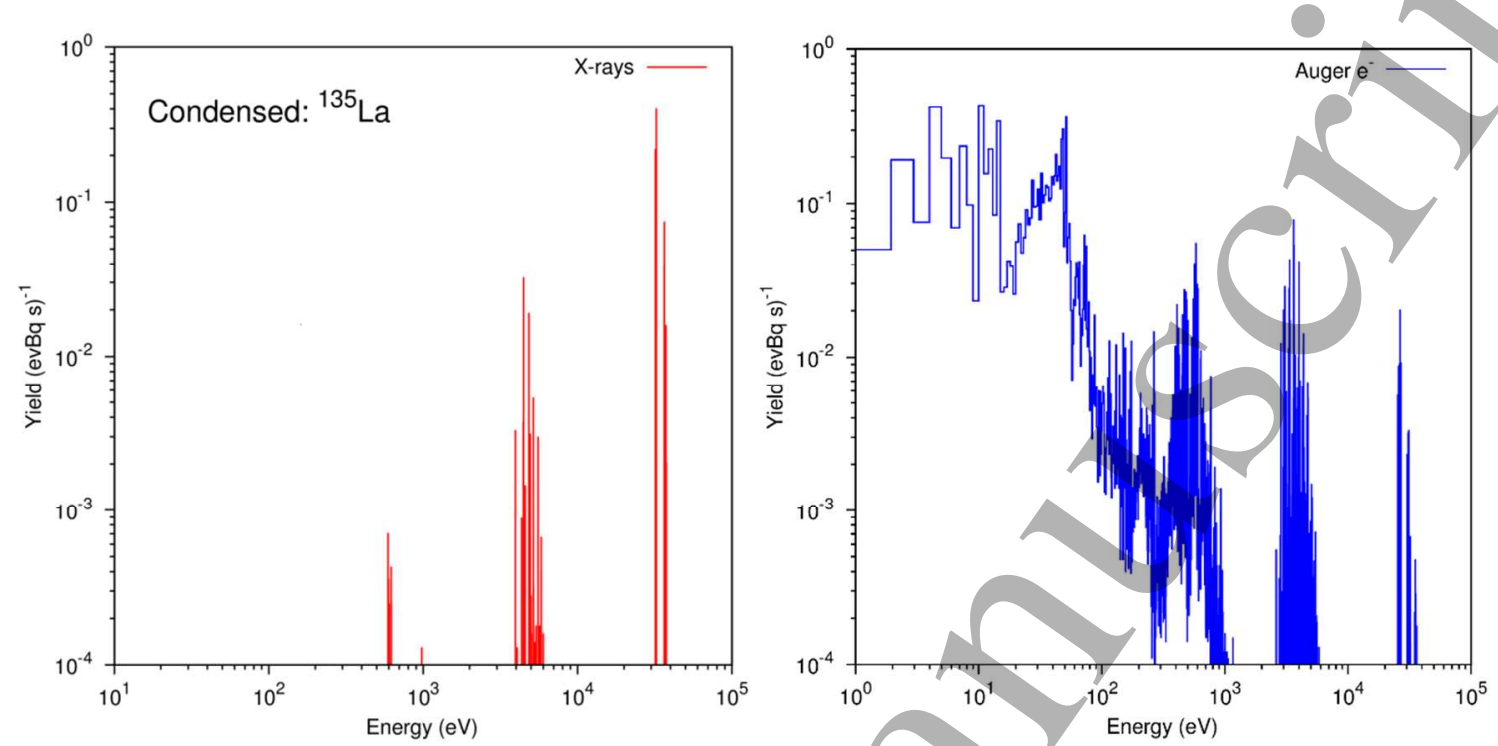

Figure 2 Histograms (bin-size $1 \mathrm{eV}$ ) showing the X-ray (red) and Auger (blue) kinetic energy spectra following the decay of ${ }^{135} \mathrm{La}$ atoms in the condensed-phase approximation of BriccEmis. These results are tabulated in Table 2.

The BrIccEmis derived spectrum is shown in Figure 2. Total energies released through X-rays and Auger electrons per decay, are 25.8 and $6.45 \mathrm{keV}$, respectively. There are on average 10.6 Auger electrons per decay ( $>97 \%$ of total) that have energies less than $4 \mathrm{keV}$. The maximum range of these very low-energy electrons is $<0.5 \mu \mathrm{m}$ in water [28]. 


\begin{tabular}{|lll} 
Auger LXY & 0.014 & 5.15 \\
CK MMX & 0.634 & 0.104 \\
Auger MXY & 1.59 & 0.538 \\
Super-CK NNN & 0.277 & 0.007 \\
CK NNX & 1.33 & 0.049 \\
Auger NXY & 4.27 & 0.039 \\
CK OOX & 1.78 & 0.009 \\
Auger OXY & 0.023 & 0.030 \\
Total & 10.9 & 0.592
\end{tabular}

Table 2: Auger average spectrum following ${ }^{135}$ La decay, the standard deviation in the total number of electrons ejected per decay is $3.2 \mathrm{e}^{-} /(\mathrm{Bq} \mathrm{s})$.

\begin{tabular}{l|c|c|} 
X-ray & Yield /decay & $\begin{array}{c}\text { Mean energy } \\
(\mathrm{keV})\end{array}$ \\
\hline $\mathrm{K} \alpha_{1}$ & 0.404 & 32.3 \\
$\mathrm{~K} \alpha_{2}$ & 0.220 & 31.9 \\
$\mathrm{~K} \beta_{1}$ & 0.075 & 36.5 \\
$\mathrm{~K} \beta_{2}$ & 0.024 & 37.4 \\
$\mathrm{~K} \beta_{3}$ & 0.039 & 36.4 \\
$\mathrm{~K} \beta_{4}$ & $<0.001$ & 37.5 \\
$\mathrm{~K} \beta_{5}$ & $<0.001$ & 36.8 \\
$\mathrm{KO} *$ & 0.003 & 37.6 \\
$\mathrm{~L}$ & 0.098 & 4.71 \\
$\mathrm{M}$ & 0.007 & 0.711 \\
$\mathrm{~N}$ & $<0.001$ & 0.123 \\
Total & 0.871 & 29.6 \\
*All other K X-rays. & \multicolumn{2}{|l}{} \\
\hline Table 3. X-ray average spectrum following ${ }^{135}$ La decay.
\end{tabular}

232 Dosimetry

233 The S-factors derived in this work are given in Table 4. From these results, it is clear that the calculated 234 cellular S-factors based on the BrIccEmis derived Auger spectrum of ${ }^{135} \mathrm{La}$ are different from those 235 obtained when using the spectrum from NuDat 2 [14]. The BrIccEmis derived spectrum yields higher $236 \mathrm{~S}(\mathrm{~N} \leftarrow \mathrm{N})$ but lower $\mathrm{S}(\mathrm{N} \leftarrow \mathrm{Cy})$ and $\mathrm{S}(\mathrm{N} \leftarrow \mathrm{CS})$. These changes follow from the fact that the BrIccEmis 

derived spectrum has a higher overall yield of low-energy Auger electrons and a slightly lower overall yield of the higher-energy K-shell Auger electrons. The low-energy emissions are more dose-intensive when inside the cell nucleus, while the higher energy emissions are more effective at supplying dose to the nucleus when they are localized in cytoplasm and on cell surfaces. This is because low energy emissions have a lower probability of reaching the nucleus from these compartments

242 The S-factors calculated using the COOLER formalism show increased dose for the compartments $(\mathrm{N} \leftarrow$ $243 \mathrm{Cy})$ and $(\mathrm{N} \leftarrow \mathrm{CS}), 38 \%$ and $89 \%$ respectively while $(\mathrm{N} \leftarrow \mathrm{N})$ showed a $5 \%$ decrease, using this newly 244 calculated spectrum as compared to the MIRDCell formalism.

246 Comparing the dose delivered from ${ }^{135} \mathrm{La}$ to that of ${ }^{177} \mathrm{Lu}$ and ${ }^{90} \mathrm{Y}$, it is seen that for $(\mathrm{N} \leftarrow \mathrm{N}),{ }^{135} \mathrm{La}$ delivers 247 a higher dose to the nucleus than ${ }^{177} \mathrm{Lu}$ and ${ }^{90} \mathrm{Y}$. However, this is not the case when the decay occurs in 248 the cytoplasm or on the cell surface. Comparing the new ${ }^{135} \mathrm{La}$ spectrum to ${ }^{177} \mathrm{Lu}$, the dose ratio is 4 and 2495.5 for the compartments $(\mathrm{N} \leftarrow \mathrm{Cy})$ and $(\mathrm{N} \leftarrow \mathrm{CS})$ respectively. This means that four disintegrations of $250 \quad{ }^{135} \mathrm{La}$ are needed to deliver absorbed dose, equal to that associated with a single disintegration of ${ }^{177} \mathrm{Lu}$ in 251 the cytoplasm. For ${ }^{90} \mathrm{Y}$ the dose ratios are 1.3 and 2, respectively. However, the number of interest when 252 assessing the potential of a therapeutic isotope is not the dose delivered per disintegration, but the target253 to-normal ratio i.e., the dose delivered to the target divided by the dose delivered to normal tissue.

254

\begin{tabular}{|c|c|c|c|c|}
\cline { 2 - 5 } \multicolumn{1}{c|}{} & \multicolumn{2}{c|}{ MIRDCell } & \multicolumn{2}{c|}{ COOLER } \\
\cline { 2 - 5 } S-value & BrIccEmis & NuDat 2 spectrum & BrIccEmis & NuDat 2 spectrum \\
\hline $\mathrm{S}(\mathrm{N} \leftarrow \mathrm{N})$ & $1.29 \mathrm{E}-03$ & $9.51 \mathrm{E}-04$ & $1.23 \mathrm{E}-03$ & $9.45 \mathrm{E}-04$ \\
\hline $\mathrm{S}(\mathrm{N} \leftarrow \mathrm{Cy})$ & $6.81 \mathrm{E}-05$ & $7.06 \mathrm{E}-05$ & $9.39 \mathrm{E}-05$ & $1.02 \mathrm{E}-04$ \\
\hline $\mathrm{S}(\mathrm{N} \leftarrow \mathrm{CS})$ & $3.09 \mathrm{E}-05$ & $3.46 \mathrm{E}-05$ & $5.84 \mathrm{E}-05$ & $6.41 \mathrm{E}-05$ \\
\hline
\end{tabular}

Table 4: Comparison of the cellular S-factors [Gy/(Bq*s)] for ${ }^{135}$ La calculated in MIRDCell (left) and COOLER (right) using the new Monte Carlo based Auger spectrum and, as reference, the input spectrum available in the NuDat 2 database [14].

\begin{tabular}{|c|c|c|c|}
\hline & COOLER & \multicolumn{2}{|c|}{ MIRDCell } \\
\hline S-value & $\begin{array}{c}{ }^{135} \mathrm{La} \\
\text { BrIccEmis }\end{array}$ & $\begin{array}{c}{ }^{177} \mathrm{Lu} \\
\text { MIRD }\end{array}$ & $\begin{array}{c}{ }^{90} \mathrm{Y} \\
\text { MIRD }\end{array}$ \\
\hline $\mathrm{S}(\mathrm{N} \leftarrow \mathrm{N})$ & $1.23 \mathrm{E}-03$ & $1.05 \mathrm{E}-03$ & $2.54 \mathrm{E}-04$ \\
\hline $\mathrm{S}(\mathrm{N} \leftarrow \mathrm{Cy})$ & $9.39 \mathrm{E}-05$ & $2.78 \mathrm{E}-04$ & $9.09 \mathrm{E}-05$ \\
\hline $\mathrm{S}(\mathrm{N} \leftarrow \mathrm{CS})$ & $5.84 \mathrm{E}-05$ & $1.72 \mathrm{E}-04$ & $6.15 \mathrm{E}-05$ \\
\hline
\end{tabular}


Table 5 A comparison of the cellular S-factor $\left[\mathrm{Gy} /\left(\mathrm{Bq}^{*} \mathrm{~s}\right)\right]$ of ${ }^{135}$ La calculated in COOLER, to those of the traditional $\beta$-emitting therapeutic radionuclides ${ }^{177}$ Lu and ${ }^{90} \mathrm{Y}$ calculated in MIRDCell.

The relative merit of ${ }^{135} \mathrm{La}$ for single cell or small cell-cluster therapy as compared with the "standard" therapeutic nuclides ${ }^{177} \mathrm{Lu}$ and ${ }^{90} \mathrm{Y}$ is obvious in Figure 3. It shows the fraction of emitted electron energy absorbed within spheres of ever growing radii. Only ${ }^{135} \mathrm{La}$ is treated using both the COOLER and the Cole stopping power approach, seeing that the COOLER formalism, at present, is not capable of handling the high electron energies associated with ${ }^{177} \mathrm{Lu}$ and ${ }^{90} \mathrm{Y}$ decay (currently limited to $50 \mathrm{keV}$ ).

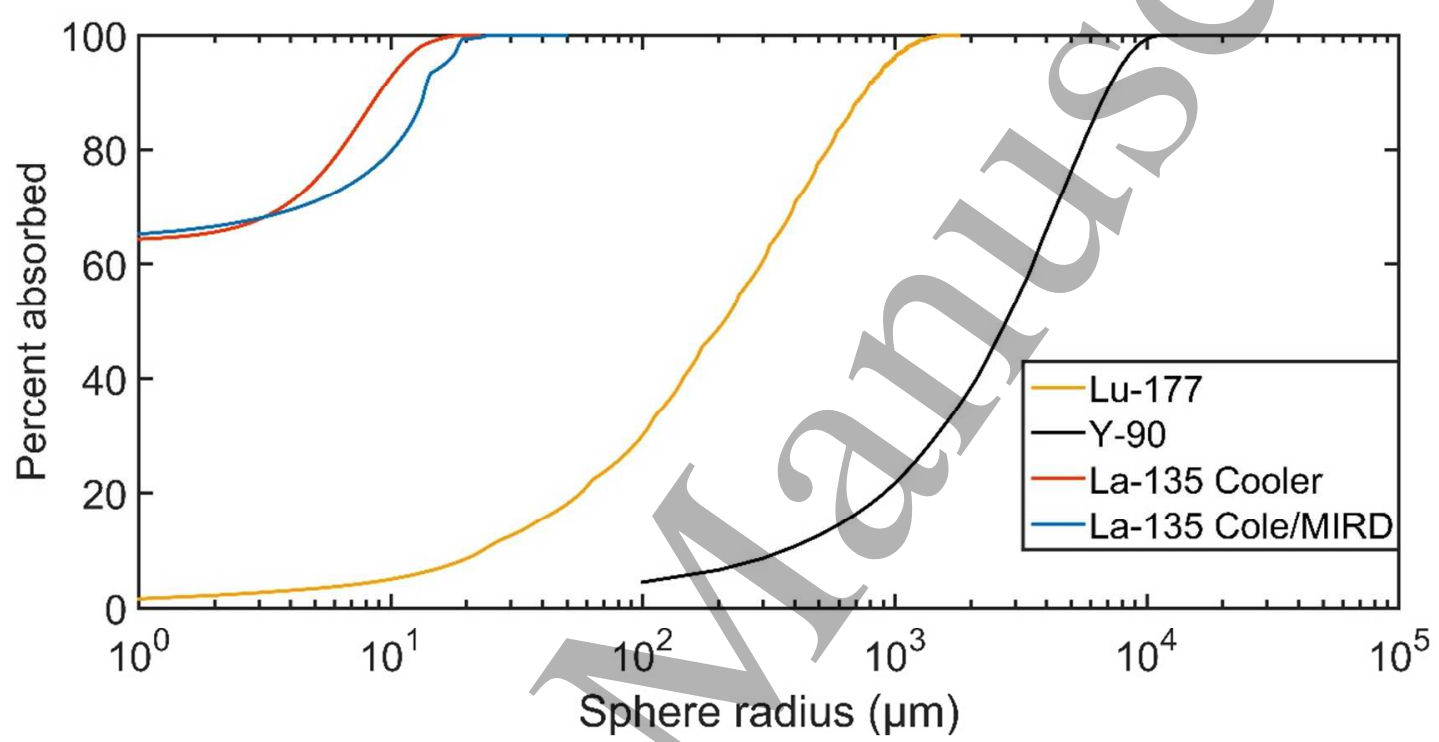

Figure 3 Fraction of electron kinetic energy absorbed within spheres as function of sphere radius. The energy deposition is calculated using the Cole stopping power as stated and used in the introduction of MIRD Cellular S-values [24], with exception of the "La-135 Cooler" curve (red) which was calculated using the COOLER code. The input for the continuous beta spectra are taken from RADAR[29] $\left({ }^{90} \mathrm{Y}\right.$ and $\left.{ }^{17} \mathrm{Lu}\right)$, the conversion- and Auger electrons from NuDat 2, except for ${ }^{135} \mathrm{La}$, where the new, calculated Auger spectrum is used. Photons, including bremsstrahlung, are omitted.

Figure 3 however, hides the full impact of the Auger emissions from ${ }^{135} \mathrm{La}$. In very small spheres (radius less than the diameter of cell nucleus) surrounding a ${ }^{135} \mathrm{La}$ decay, the local dose is very high. This can be seen in Figure 4 which shows the dose-point kernel for ${ }^{135} \mathrm{La}$ as calculated with the new spectrum and both the COOLER and the Cole stopping power formalisms. 
296 When turning to the emissions of ${ }^{135} \mathrm{La}$, we show the results of calculations using the BrIccEmis code 297 from Lee et al. [16]. Importantly this method accounts for multiple vacancies during the cascade. Notably, 298 if the atomic transition energies are approximated using neutral binding energies, and thereby neglecting 299 the effect of multiple vacancies, this could give rise to multiple energies for a given atomic transition due

Figure 4: Dose-point kernels for ${ }^{135}$ La Auger electron emissions (X-rays are not included) for both the COOLER and Cole/MIRD methodologies. In both cases, the calculations were performed using the Auger spectrum obtained from the BrIccEmis simulation.

\section{Discussion:}

The Auger emitter ${ }^{135} \mathrm{La}$ is a potential radionuclide for targeted internal therapy. From the view of production and purification, the route via proton irradiation of ${ }^{\text {nat }} \mathrm{Ba}$ is straightforward. Clearly, the rate of production and the radionuclidic purity of ${ }^{135} \mathrm{La}$ could be improved by irradiating enriched ${ }^{135} \mathrm{Ba}$, but further target development would be required to allow either irradiation of a barium oxide or salt, or to accommodate reduction of recycled ${ }^{135} \mathrm{Ba}^{2+}$ after the separation procedure. While the overall separation factor achieved in this report is not impressive $\sim 10^{2}$, the fact that high labeling effective specific activity is obtained demonstrates that rigorous separation is not critical. Here, the measured effective specific activity is a positive indicator for the expected labeling yield. The value measured by DTPA titration of $(70.4 \pm 20.0 \mathrm{GBq} / \mu \mathrm{mol})$ corresponds well with what would be expected from the ICP analysis. If, for some applications, higher effective specific activities are required, an additional step to ensure the removal of iron and manganese could be employed [30]. It should be noted that the exact impurity profile of competing metals will depend on the initial purity of the barium stock used.

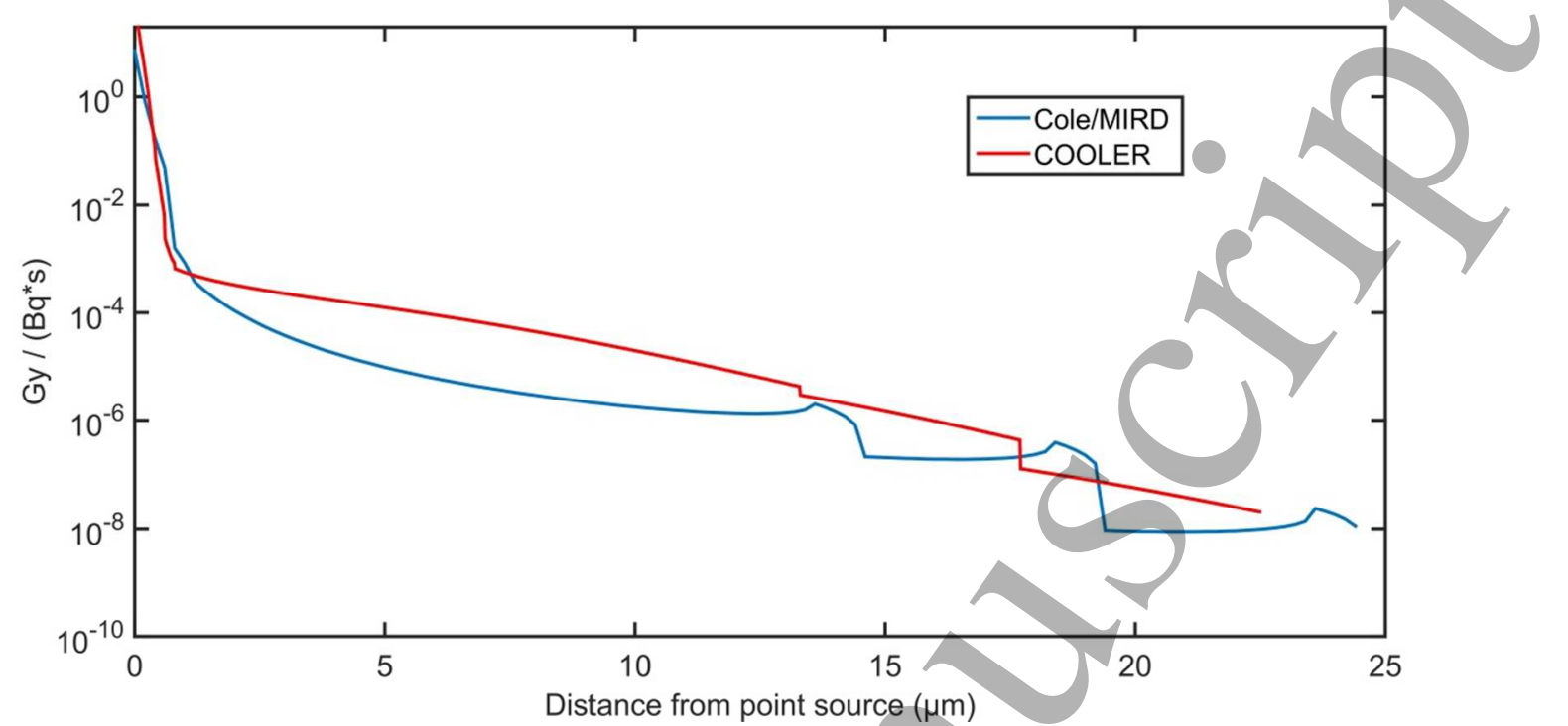


to the stochastic nature of the Auger cascade. Falzone \& Lee et al. showed that MIRD RADTABS disagree with the experimental L-Auger spectrum of ${ }^{131} \mathrm{Cs}$ and demonstrated that the theoretical L-Auger energy spectrum of ${ }^{131} \mathrm{Cs}$ agreed with experiment only when the effect of multiple vacancies was taken 303 into account [27,31].

304

In the present case, the use of the newly calculated Auger spectrum does not result in dramatically different cellular dosimetry. However, the exact shape of the spectrum at low energies can become extremely important as cellular and subcellular targeting becomes more exact. This is because the 308 expected biological effect of Auger emitters may not solely rely on the dose, but also on the RBE of the 309 low energy electrons. An important part of the Auger emitter concept is the expectation of an RBE larger 310 than that of conventional gamma or beta irradiation. RBE is the measure used to compare different types 311 of radiation gray-to-gray, assessing the biological damage done. A common measure for the biological 312 damage is DNA double-strand breaks, which are potentially more likely to occur in close proximity to the 313 decay site of an Auger emitter. For higher energy electron and beta emissions $(>20 \mathrm{keV})$, creating a 314 double-strand break with a single pass of an electron is highly unlikely because the mean path length 315 between subsequent ionization events is much larger than the distance between the DNA strands. 316 Therefore multiple electrons stemming from multiple decays have to pass through or get in close 317 proximity to the same area of the DNA/strand to create a double-strand break. With an Auger emitter this 318 is not the case. Due to the multiple electrons emitted in a single decay $\left(10.9 \pm 3.2 /\right.$ decay for $\left.{ }^{135} \mathrm{La}\right)$ only a 319 single decay is potentially enough to cause the double-strand break if the decay occurs close to the DNA. 320 Additionally, the decaying atom would find itself highly ionized due to multiple emissions of Auger 321 electrons and thus could be highly oxidizing to the immediate environment. From a physical perspective, 322 these two factors combined should result in an RBE much higher than 1, meaning more effective therapy 323 per gray deposited. A recent paper has described how the cell surface is more radiosensitive than assumed 324 in MIRD [32]. The calculations presented in this paper only consider dose to the nucleus, however 325 incorporating the cell surface as a sensitive target would make the case for ${ }^{135}$ La even stronger, seeing that 326 this would decrease the importance of internalization.

328 It is also important to understand that the low amount energy emitted per decay of ${ }^{135}$ La does not preclude 329 effective therapy. For therapeutic benefit, the relevant metric is not the absolute dose-per-decay but the 330 ratio of the dose absorbed by the target to the dose absorbed by the surrounding healthy tissue. 331 Commonly, the limiting factor is the absorbed dose in healthy tissue immediately surrounding the 332 targeted cell, or the absorbed dose in clearance organs. When considering the absorbed dose to the 333 immediate surroundings, the benefit of using ${ }^{135} \mathrm{La}$ is clear from Figure 3 and Figure 4, where the absence 
334 of higher energy beta electrons and the limited Auger-electron range of ${ }^{135}$ La results in dramatically 335 reduced dose beyond one cell diameter. As is the case with any Auger emitter, there are clear benefits of 336 using ${ }^{135} \mathrm{La}$ when the target being treated is very small.

338 Conclusion:

339 A method has been developed allowing the production of clinically relevant amounts of ${ }^{135} \mathrm{La}$ using 340 medical cyclotrons. The developed purification method is fast, robust and essentially loss-less. ${ }^{135} \mathrm{La}$ has a 341 well-suited half-life for therapy. The calculated cellular dosimetry shows that the emissions from ${ }^{135} \mathrm{La}$ 342 lead to cellular S-values that are promising for internal radionuclide therapy of very small targets, with 343 dosimetry superior to ${ }^{177} \mathrm{Lu}$ and ${ }^{90} \mathrm{Y}$ at single-cell dimension. This along with the mounting evidence of 344 Auger emitters having an RBE $>1$ strongly motivates further research in application of Auger emitters in 345 treatment of single cancerous cells and micro-metastasis.

346

Acknowledgements: 348

349 This work was supported by the European Union Seventh Framework Programme FP7/2007-2013 under 350 Grant 602820 (Mathias), and by the Australian Research Council Discovery Grant DP14 0103317.

References

353 [1] Pfeifer AK, Gregersen T, Grønbæk H, Hansen CP, Müller-Brand J, Herskind Bruun K, et al. 354 355 356

359 [3] Müller C, Reber J, Haller S, Dorrer H, Köster U, Johnston K, et al. Folate receptor targeted alpha360 therapy using terbium-149. Pharmaceuticals 2014;7:353-65. doi:10.3390/ph7030353.

361 [4] Müller C, Reber J, Haller S, Dorrer H, Bernhardt P, Zhernosekov K, et al. Direct in vitro and in 362 vivo comparison of $161 \mathrm{~Tb}$ and $177 \mathrm{Lu}$ using a tumour-targeting folate conjugate. Eur J Nucl Med 363 Mol Imaging 2014;41:476-85. doi:10.1007/s00259-013-2563-z.

364 [5] Müller C, Zhernosekov K, Köster U, Johnston K, Dorrer H, Hohn A, et al. A unique matched 365 366 an in vivo proof-of-concept study with a new receptor-targeted folate derivative. J Nucl Med quadruplet of terbium radioisotopes for PET and SPECT and for $\alpha$ - and $\beta$-radionuclide therapy: 
2012;53:1951-9. doi:10.2967/jnumed.112.107540.

[6] Grünberg J, Lindenblatt D, Dorrer H, Cohrs S, Zhernosekov K, Köster U, et al. Anti-L1CAM radioimmunotherapy is more effective with the radiolanthanide terbium-161 compared to lutetium-177 in an ovarian cancer model. Eur J Nucl Med Mol Imaging 2014;41;:1907-15. doi:10.1007/s00259-014-2798-3.

[7] Kassis AI. Molecular and cellular radiobiological effects of Auger emitting radionuclides. Radiat Prot Dosimetry 2011;143:241-7. doi:10.1093/rpd/ncq385.

[8] Howell RW, Kassis AI, Adelstein SJ, Rao D V, Wright HA, Hamm RN, et al. Radiotoxicity of platinum-195m-labeled trans-platinum (II) in mammalian cells. Radiat Res 1994;140:55-62. doi: $10.2307 / 3578568$.

[9] Azure MT, Sastry KSR, Archer RD, Howell RW, Rao D V. Microseale Synthesis of Carboplatin Labels with the Auger Emitter Platinum-193m: Radiotoxicity Versus Chemotoxicity og the Antitumor Drug in Mammalian Cells. AAPM Symp. Ser. No.8, 1992.

[10] Kassis AI. Cancer therapy with Auger electrons: are we almost there? J Nucl Med 2003;44:147981.

[11] Abel EP, Clause HK, Fonslet J, Nickles RJ, Severin GW. The Half-lives of 132La and 135La. arXiv.org 2017:1-11.

[12] Fonslet J, Tran T, Quan-Lee B, Severin G. 135La for Auger-based therapy: preparation, imaging and emissions. J Label Compd Radiopharm 2015;58:S24.

[13] Singh B, Rodionov AA, Khazov YL. Nuclear Data Sheets for A = 135. Nucl Data Sheets 2008;109:517-698. doi:10.1016/j.nds.2008.02.001.

[14] Nudat 2 n.d. http://www.nndc.bnl.gov/nudat2/ (accessed May 30, 2017).

[15] Lee BQ, Kibédi T, Stuchbery E, Robertson K. Atomic radiations in the decay of medical radioisotopes: a physics perspective. Comput Math Methods Med 2012;2012:651475. doi:10.1155/2012/651475.

[16] Lee BQ, Nikjoo H, Ekman J, Jönsson P, Stuchbery AE, Kibédi T. A stochastic cascade model for Auger-electron emitting radionuclides. Int J Radiat Biol 2016;92:641-53. doi:10.3109/09553002.2016.1153810.

[17] Prescher K, Peiffer F, Stueck R, Michel R, Bodemann R, Rao MN, et al. Thin-target cross sections of proton-induced reactions on barium and solar cosmic ray production rates of xenon-isotopes in lunar surface materials. Nucl Inst Methods Phys Res B 1991;53:105-21. doi:10.1016/0168- 
$398 \quad 583 X(91) 95645-\mathrm{T}$.

399 [18] Tárkányi F, Ditrói F, Király B, Takács S, Hermanne A, Yamazaki H, et al. Study of activation 400 cross sections of proton induced reactions on barium: Production of 131Ba 131Cs. Appl Radiat 401 Isot 2010;68:1869-77. doi:10.1016/j.apradiso.2010.03.010.

402 [19] Severin GW, Gagnon K, Engle JW, Valdovinos HF, Barnhart TE, Nickles RJ. 44gSc from metal calcium targets for PET. AIP Conf Proc 2012;1509:125-8. doi:10.1063/1.4773953.

[20] Vaziri B, Wu H, Dhawan AP, Du P, Howell RW. MIRD pamphlet No. 25: MIRDcell V2.0 405 software tool for dosimetric analysis of biologic response of multicellular populations. J Nucl Med 2014;55:1557-64. doi:10.2967/jnumed.113.131037.

407

[21] Goddu SM, Howell RW, Rao D V. Cellular dosimetry: absorbed fractions for monoenergetic 408 electron and alpha particle sources and S-values for radionuclides uniformly distributed in different cell compartments. J Nucl Med 1994;35:303-16.

410

[22] Siragusa M, Baiocco G, Fredericia PM, Friedland W, Groesser T, Ottolenghi A, et al. The 411 COOLER Code: A Novel Analytical Approach to Calculate Subcellular Energy Deposition by Internal Electron Emitters. Radiat Res 2017;188:204-20. doi:10.1667/RR14683.1.

413 [23] Friedland W, Dingfelder M, Kundrát P, Jacob P. Track structures, DNA targets and radiation 414

[24] Cole A. Absorption of 20-eV to 50,000-eV Electron Beams in Air and Plastic. Radiat Res effects in the biophysical Monte Carlo simulation code PARTRAC. Mutat Res - Fundam Mol Mech Mutagen 2011;711:28-40. doi:10.1016/j.mrfmmm.2011.01.003.

418 [25] Lee BQ, Kibédi T, Stuchbery AE. Auger yield calculations for medical radioisotopes. EPJ Web Conf 2015;91:7. doi:10.1051/epjconf/20159100007.

[27] Falzone N, Lee BQ, Fernandez-Varea JM, Kartsonaki C, Stuchbery AE, Kibedi T, et al. Absorbed dose evaluation of Auger electron-emitting radionuclides: impact of input decay spectra on dose point kernels and S -values. Phys Med Biol 2017;62:2239-53. doi:10.1088/1361-6560/aa5aa4.

425 [28] Emfietzoglou D, Nikjoo H. Accurate electron inelastic cross sections and stopping powers for 426 liquid water over the $0.1-10 \mathrm{keV}$ range based on an improved dielectric description of the Bethe surface. Radiat Res 2007;167:110-20. doi:10.1667/RR0551.1.

428 [29] RADAR Home n.d. http://www.doseinfo-radar.com/RADARHome.html (accessed May 30, 2017). 
429 [30] Fonslet J, Tietze S, Jensen AI, Graves SA, Severin GW. Optimized procedures for manganese-52:

Production, separation and radiolabeling. Appl Radiat Isot 2017;121:38-43. doi:10.1016/j.apradiso.2016.11.021.

432 [31] Eckerman KF, Endo A. MIRD: radionuclide date and decay schemes. Society of Nuclear Medicine; 2008.

434 [32] Paillas S, Ladjohounlou R, Lozza C, Pichard A, Boudousq V, Jarlier M, et al. Localized 